\title{
System Exergy: System Integrating Physics of Launch Vehicles and Spacecraft
}

\author{
Michael D. Watson* \\ NASA Marshall Space Flight Center, Huntsville, Alabama, USA
}

\begin{abstract}
System Engineering of launch vehicles and spacecraft is a challenging and complex under taking. There are many diverse systems which must be integrated and balanced to produce an effective design. This involves a multiplicity of individual engineering relationships that are difficult to integrate and even more difficult to define in a best balance. Integration efforts involve many different approaches from process management to mass balance. But these approaches either do not directly address the launch vehicle or spacecraft performance or require many adjustments to be made to discover a balance. The system integrating physics, derived from the fundamental physics of the system, is the key to identifying a fully integrated system performance measure. Launch vehicles and spacecraft are thermodynamic systems with performance defined by thermodynamic properties. Thus, thermodynamic exergy, which integrates all of the systems thermodynamic properties, provides the system integrating relationships. This provides a basis for determining the most efficient design from among many different configuration options and for guiding the design activities from an integrated system level. This paper explores the current physics relationships used in launch vehicle system design and demonstrates that thermodynamic exergy provides a more explicit and complete approach to system integration.
\end{abstract}

\section{Nomenclature}

$C_{r} \quad=\quad$ individual system constraint

$C_{l} \quad=\quad$ system constraint of $1^{\text {th }}$ system

$d_{\text {moon,initial }}=\quad$ initial vehicle distance to moon $(\mathrm{m}$ or $\mathrm{ft})$

$d_{\text {moon,final }}=$ final vehicle distance to moon $(\mathrm{m}$ or $\mathrm{ft})$

\footnotetext{
* Systems Engineer, Systems Engineering Office, MS EE11, NASA MSFC, Huntsville, AL 35812
} 


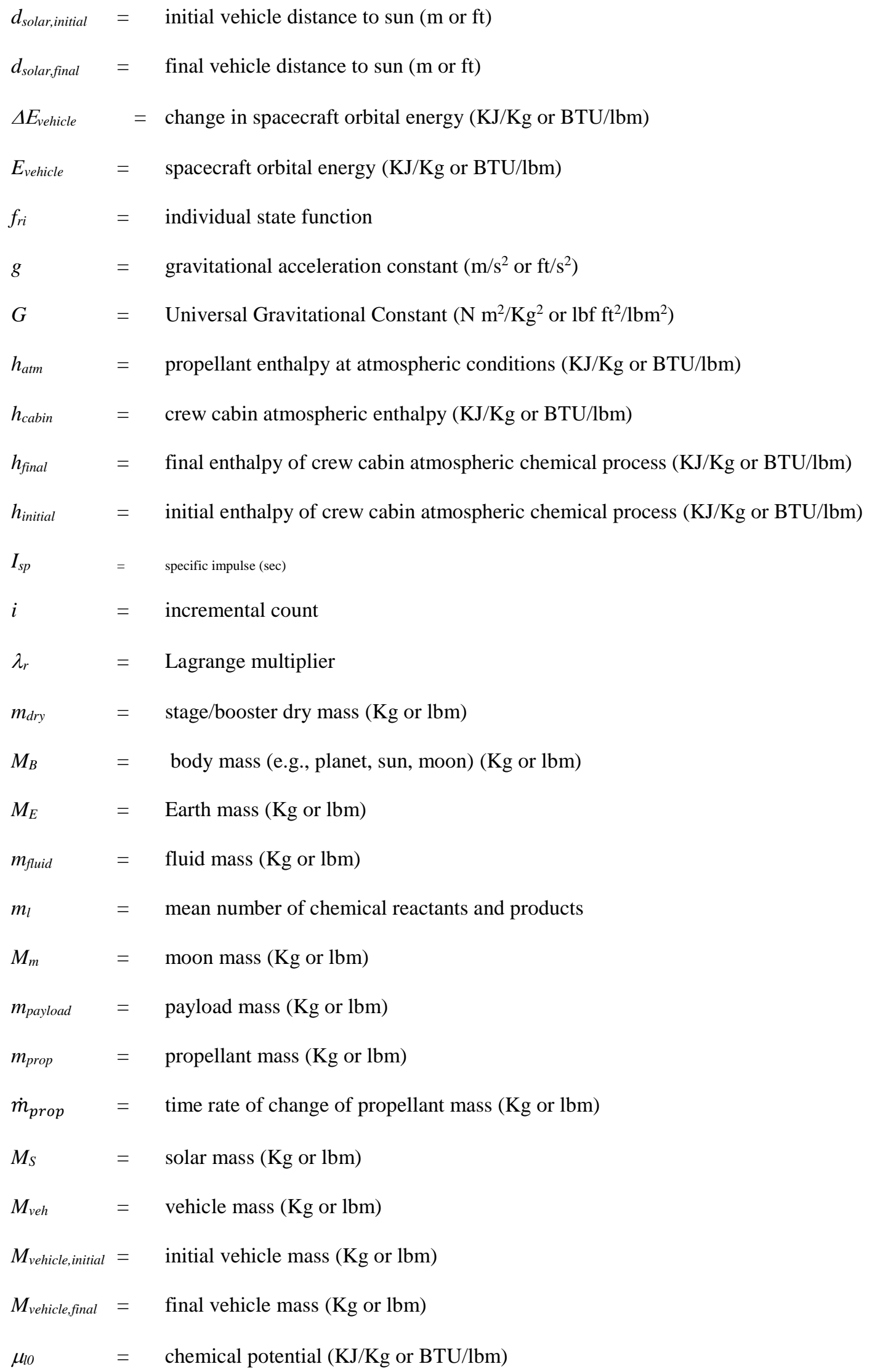




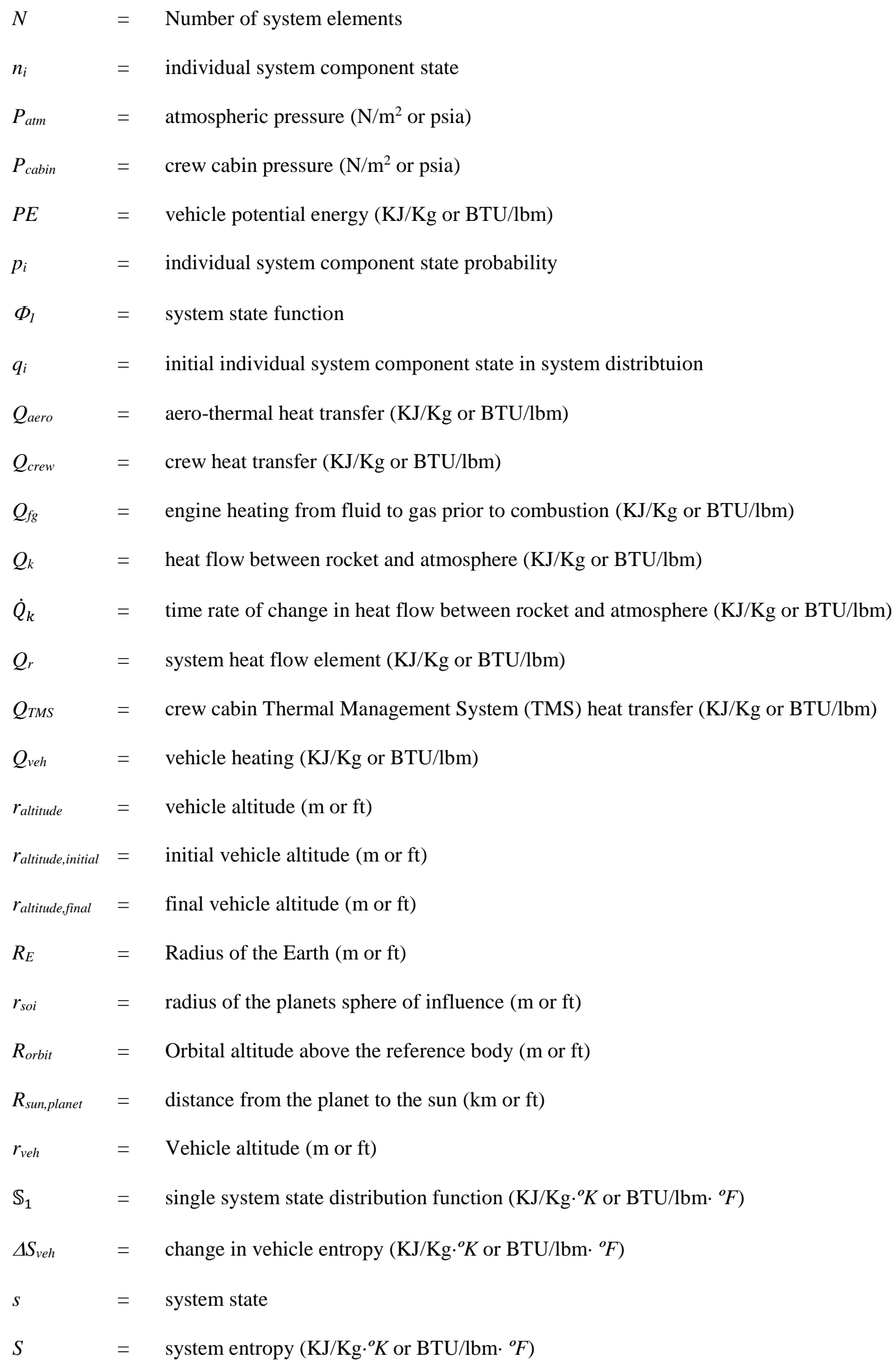




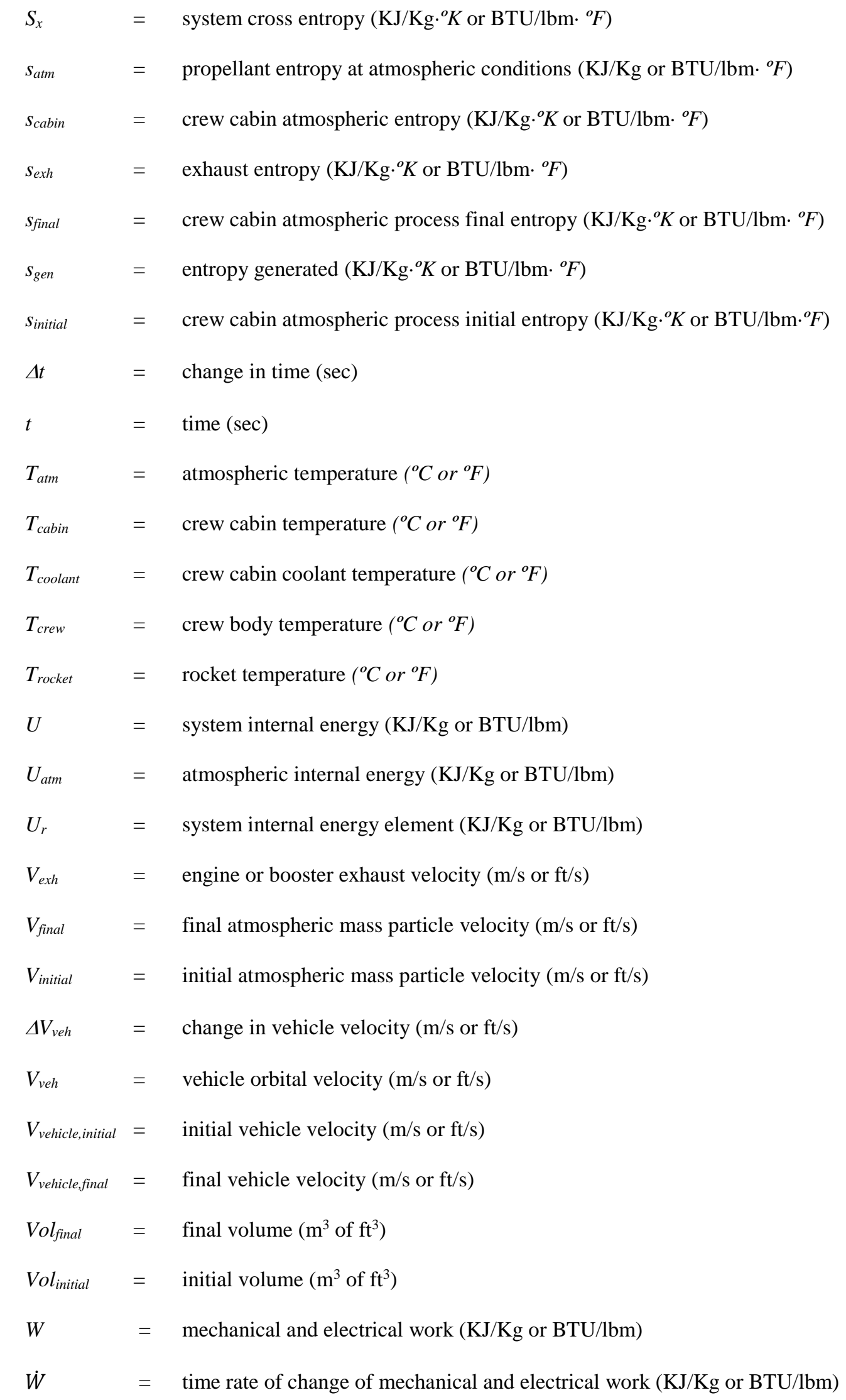




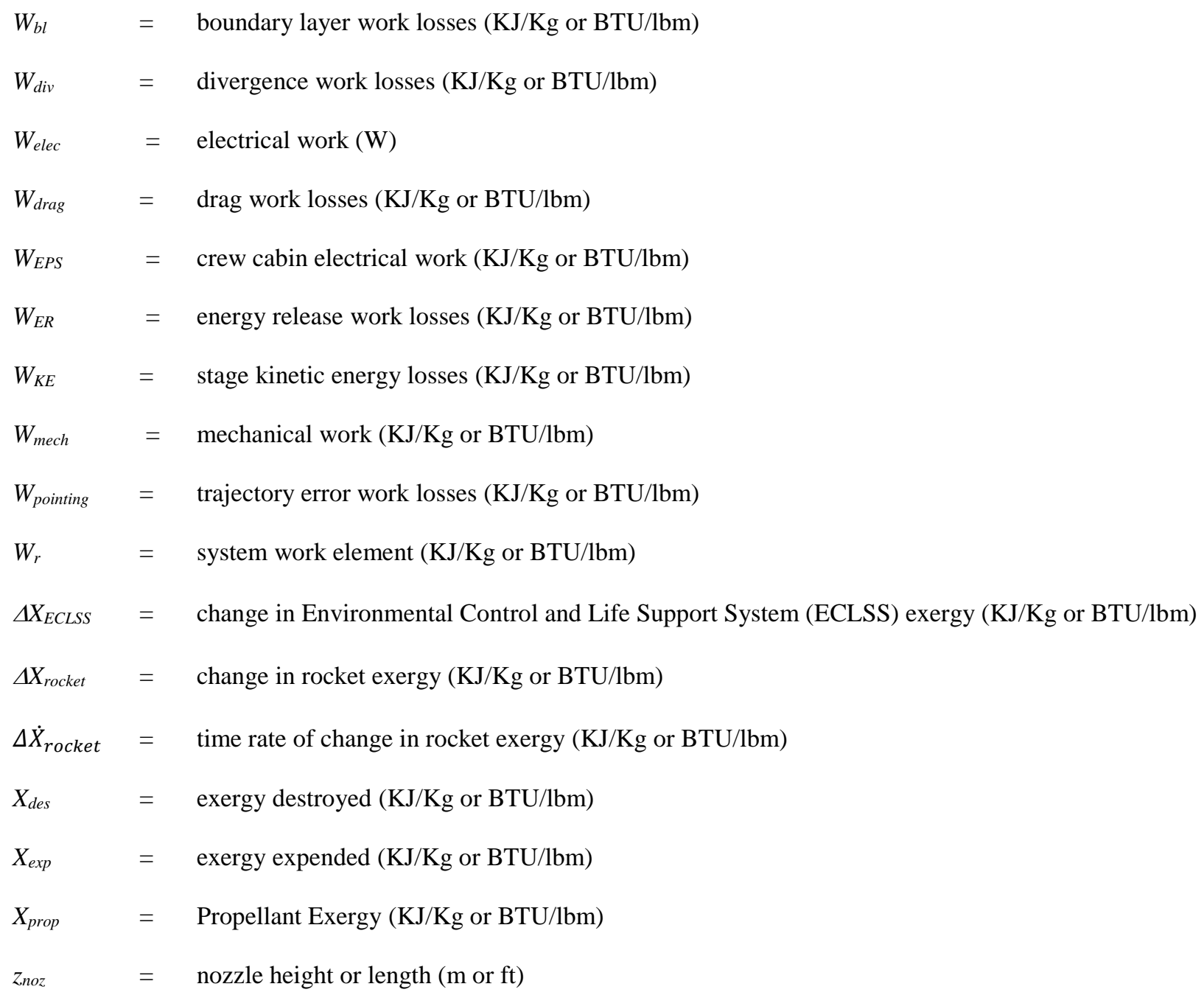

\section{Introduction}

$S_{\mathrm{r}}$ YSTEMS are driven by energy and limited by entropy. Exergy is the thermodynamic property which combines both of these thermodynamic laws. As such, many applications can be found for the application of exergy in many different system types. Exergy has been applied to the design and analysis of various system types including aeronautic, biological, control, ecological, electrical power, heat transfer, and life support showing its broad application. [1,2] In aerospace application, systems exergy has mainly been applied to aircraft design, analysis, and optimization. It has been applied in various system contexts including lunar base thermal energy designs [3], aircraft system design [4,5,6,7], analysis, and optimization, aircraft engine analysis $[8,9,10,11,12]$, aircraft environmental control [13], pulsed detonation power devices [14], and hypersonics [1,15]. Interesting comparisons between exergy 
balance equation and the Breguet range equation have also been done for aircraft [16]. This comparison shows that exergy analysis provides more details in the system performance than the Breguet equation. This is a similarity that will be shown between the exergy balance equation and the rocket equation. Several important questions were posed in a paper addressing issues with systems engineering in modern practice [17]. This paper will address aspects of system efficacy and system efficiency for a launch vehicle. Specific application of exergy to systems engineering has been considered for aircraft [18]. Statistical techniques using exergy for system integration for aircraft has also been discussed [19]. The basic construction of the exergy balance equation has been well addressed for aircraft and general thermodynamic systems $[20,21,22]$. With all this basis for aircraft, very little has been done in the application of system exergy analysis to launch vehicles and spacecraft. The author has contributed to a set of early analysis papers on launch vehicles [23,24,25,26,27] and spacecraft life support systems [28], and sponsored work on the application of exergy to systems engineering. This paper provides the foundational work and derivations on which these analysis and application papers are built. Ref. [1] also has a section on exergy analysis of the Saturn V. However, the equations are derived from a hypersonics perspective and are based on enthalpy terms making the exhaust velocity term implicit. This makes exergy application to space vehicles difficult to see. This paper will show the exergy balance equation with the engine/motor exhaust velocity as an explicit parameter in exergy balance clearly showing the relationship to rocket design. Aerospace engineers have traditionally used the rocket equation, which acts as a constraint on the system design solution, to guide basic selection of propulsion system thrust and stage masses. This is not an integrated approach but a series of partially integrated steps. This paper will demonstrate how the exergy balance equation provides a full integration of launch vehicle and spacecraft parameters providing a key systems engineering design and analysis tool.

\section{Traditional Design Approach}

Traditional approaches to launch vehicle and spacecraft design use some basic relationships that only partially represent the vehicle. These approaches only partially integrate the vehicle and must be adjusted to incorporate various loss effects during system design. These approaches are briefly described in this section.

\section{A. Rocket Equation}


Traditionally, launch vehicle and spacecraft bus design has followed Konstantin Tsiolkovsky's rocket equation [29]:

$$
\Delta V_{\text {veh }}=V_{\text {exh }} \ln \frac{M_{\text {vehicle, } \text { initial }}}{M_{\text {vehicle,final }}}
$$

Tsiolkovsky first derived this relationship from the basic momentum relationships in 1903 and it has served as the rocket designer's fundamental relationship for the last century. In applying the rocket equation in launch vehicle design, you assume that the vehicle starts at rest on the pad and ends at a velocity determined by the orbit given by [30]

$$
V_{v e h}=\sqrt{2 G M_{E}\left(\frac{1}{R_{E}}-\frac{1}{r_{\text {orbit }}}\right)} .
$$

Thus, the vehicle velocity is defined by the orbit regardless of the vehicle configuration. This then leaves the mass splits of the vehicle and the propulsion system exhaust velocity as design variables of interest. Given that there are discrete engine and booster configurations with specific thrust levels (and not a continuum in practice), the choice of the engine or motor determines the exhaust velocity parameter early in design. This leaves the mass splits for the vehicle to balance in design. The engines and/or boosters are often selected given the vehicle gross lift off weight (GLOW) ( $\left.\mathrm{M}_{\mathrm{vehicle}, \text { initial }}\right)$ and the final payload orbital insertion mass $\left(\mathrm{M}_{\mathrm{vehicle}}\right.$,final $)$. Thus, in an equation derived from momentum relationships with the velocities fixed, only mass is left as a design variable. Rocket design then follows this path and much of the system design is focused on mass splits and mass management. Some very creative and instructive ways of looking at the mass relationships have been addressed in recent publications. [31]

There are many important vehicle characteristics which affect this relationship but which do not appear directly in this equation. Gravity losses (i.e., vehicle potential energy) are not contained in the momentum relationships though it is a part of the orbital velocity relationship. Thus, while an important factor, it must be dealt with separately from the rocket equation. Similarly, other vehicle loss components are not accounted for in the momentum relationship including vehicle drag, aero-thermal heating, pointing errors, etc. These must all be handled separately, and while there is coupling between them, they are calculated separately and iterated within the design process to determine a balance (or "closed" design solution).

In a similar fashion, engine and booster expected performance must incorporate losses from several factors and discount these from the ideal performance relationships. These consider such factors for a liquid engine as energy release efficiency, kinetic efficiency, divergence efficiency, and boundary layer efficiency [32]. 
All of these loss factors are defined separately and applied through a set of vehicle kinematic trajectory relationships. These are iterated and tuned until the selected engine and/or booster performance meets the mass relationships as defined by the rocket equation. In this sense, the rocket equation serves more as guidance on directions to go with the design and a final verification of a particular design solution. This diverse integration approach provides a check on the solution but does not yield an assessment of how well the configuration performs nor does it integrate all of the various vehicle subsystems and environments.

One final observation from thermodynamics: mass is a system property, not a system state. [33] Thus, traditional rocket design is based on optimization of a single system property rather than the system as whole. The next subsection considers other important properties in launch vehicle and spacecraft bus design.

\section{B. Energy and Entropy}

If you want to balance a system in thermodynamics, the conservation of mass and the conservation of energy are key relationships. Eq. 2 is derived from an energy relationship and so the integrating physics of the vehicle must certainly include the energy balance. For a launch vehicle this is expressed as:

$$
\mathrm{Q}_{v e h}+\mathrm{M}_{v e h} \frac{v_{v e h}{ }^{2}}{2}+\mathrm{M}_{v e h} g r_{v e h}=\sum_{\text {engine } / \text { motor }} m_{\text {prop }}\left(h_{\text {prop }}+\frac{V_{\text {exh }}{ }^{2}}{2}+m_{\text {prop }} g z_{n o z}\right)
$$

The summation accounts for each engine and booster by stage. This equation brings in the vehicle thermal effects $\left(\mathrm{Q}_{\mathrm{veh}}=0\right.$ if an adiabatic vehicle is assumed), gravitational energy requirements (potential energy term), and engine/booster motor thrust composed of the propellant exhaust enthalpy, exhaust velocity, and fluid potential energy change (typically small, $\approx 0$ ).

Conservation of mass is also an important relationship for both Eq. (1) and Eq. (3). For a launch vehicle, conservation of mass can be written as:

$$
M_{\text {veh }}=m_{\text {payload }}+\sum_{\text {stage }}\left(m_{\text {prop }}+m_{\text {dry }}\right)
$$

This is certainly an improvement but there are many loss terms still absent in this equation. Vehicle drag and trajectory errors are certainly not represented and the efficiency of the various engine and/or booster motor components must be calculated and applied separately. If this is not done, then the launch vehicle would appear to be much more efficient (higher propulsion energy, higher vehicle kinetic energy than actually achieved). Also, the second law implications and the entropy terms for the system are not contained in the equation. 
Entropy must be included as part of the vehicle overall balance. The entropy balance equation for a launch vehicle is:

$$
\left(s_{e x h}-s_{a t m}\right)-s_{g e n}=\Delta s_{v e h}
$$

Note, that the entropy relationship includes reference to the environment (atmospheric conditions) and terms which generate system losses in the form of entropy generated (i.e., vehicle drag, pointing errors, engine efficiencies, motor efficiencies). Thus the entropy balance provides for the terms not accounted for in the energy balance.

Clearly, then these three balance equations, energy balance (3), mass balance (4), and entropy balance (5) contain the necessary terms which fully describe the vehicle state. The challenge then is how to combine these relationships into an integrated relationship and not treat them as uncoupled equations.

\section{Exergy Balance}

Exergy provides a balance of all three of these equations into a single relationship. Early references to the concept of exergy can be found in the 1940's by the Massachusetts Institute of Technology (MIT) who used the term "availability". The term exergy first appeared in Europe in the 1950's [34] and this term appears in many thermodynamic textbooks today. [35,36,37,38,39]

\section{A. Exergy Balance Definition}

A launch vehicle or spacecraft bus are control volumes. The volumes of each stack are held constant during flight. The volume does change with staging events and is treated by a summation of the control volumes in the balance equation. At staging, the volume of the vehicle changes by the volume of the dropped stage. The concept of thermodynamic exergy is derived by subtracting the $T_{\text {atm }}$ (atmospheric temperature) times the entropy balance equation minus the energy balance equation. The vehicle kinetic energy and potential energy terms are included with

the potential energy written in terms of the Newtonian Gravitational Constant which will be important for considering in-space exergy balance relationships.

This yields the system balance relationship for a control volume as: 


$$
\begin{aligned}
& \Delta X_{\text {rocket }}=\sum_{k}\left(1-\frac{T_{a t m}}{T_{\text {rocket }}}\right) Q_{k}-\left(W-P_{\text {atm }}\left(\operatorname{Vol}_{\text {final }}-\text { Vol }_{\text {initial }}\right)\right)+m_{\text {prop }} \sum_{\text {stage }}\left(\left(h_{\text {prop }}-\right.\right. \\
& \left.\left.h_{a t m}\right)-T_{a t m}\left(s_{e x h}-s_{a t m}\right)+\frac{V_{e x h}{ }^{2}}{2}+g z_{n o z}\right)+\left(M_{\text {vehicle,final }} \frac{V_{\text {vehicle,final }}^{2}}{2}-M_{\text {vehicle, initial }} \frac{V_{\text {vehicle, initial }}^{2}}{2}\right)+ \\
& \left(\frac{G M_{E} M_{\text {vehicle, initial }}}{r_{\text {altitude, }, \text { initial }}}-\frac{G M_{E} M_{\text {vehicle,final }}}{r_{\text {altitude,final }}}\right)-X_{\text {des }} .
\end{aligned}
$$

Equation 6 can also be written in the rate form by taking the time derivative of both sides. Since these are control volume systems, the flow exergy term contained within the parentheses in the summation on the right hand side is constant with respect to time for a steady flow system and $P_{a t m}\left(V o l_{\text {final }}-V o l_{\text {initial }}\right)=0$ since the volume is constant for each stage of flight. Thus, the rate form can be written as:

$$
\begin{aligned}
& \Delta \dot{X}_{\text {rocket }}=\sum_{k}\left(1-\frac{T_{\text {atm }}}{T_{\text {rocket }}}\right) \dot{Q}_{k}-\dot{W}+\dot{m}_{\text {prop }} \sum_{\text {stage }}\left(\left(h_{\text {prop }}-h_{\text {atm }}\right)-T_{\text {atm }}\left(s_{\text {exh }}-s_{\text {atm }}\right)+\frac{V_{\text {exh }}{ }^{2}}{2}+\right. \\
& \left.g z_{\text {noz }}\right)+\frac{d}{d t}\left[\left(M_{\text {vehicle, final }} \frac{V_{\text {vehicle,final }}^{2}}{2}-M_{\text {vehicle, initial }} \frac{V_{\text {vehicle, initial }}^{2}}{2}\right)+\left(\frac{G M_{E} M_{\text {vehicle, } \text { initial }}}{r_{\text {altitude, } \text { initial }}}-\frac{G M_{E} M_{\text {vehicle,final }}}{r_{\text {altitude,final }}}\right)\right]- \\
& \dot{X}_{\text {des }} \text {. }
\end{aligned}
$$

Considering the relationship in Eq. (6), the thermal heat flows, $\mathrm{Q}_{\mathrm{k}}$, are lost work with respect to contributing to vehicle motion in achieving orbit so that the heat transfer exergy can be incorporated into the $\mathrm{X}_{\mathrm{des}}$ term (and an adiabatic assumption is not required). The work term, W, can be separated into mechanical work (e.g., hydraulic work done to move the nozzles in thrust vector control) and electrical work (e.g., electrical work down for electric actuators and avionics). For the potential energy change of the exhaust gas, $\mathrm{m}_{\text {prop }} \mathrm{gz}_{\mathrm{noz}} \approx 0$ with respect to the other terms and can be removed from the equation. Also, the volume of the rocket is constant during each stage of flight such that $P_{a t m}\left(\operatorname{Vol}_{\text {final }}-\operatorname{Vol}_{\text {initial }}\right)=0$ as well. This allows the launch vehicle exergy balance to be written as:

$$
\begin{gathered}
\left.\Delta m_{\text {prop }} \sum_{\text {stage }}\left(h_{\text {prop }}-h_{\text {atm }}\right)-T_{\text {atm }}\left(s_{\text {exh }}-s_{\text {atm }}\right)+\frac{V_{e}^{2}}{2}\right)+W_{\text {mech }}+W_{\text {elec }}-X_{\text {des }}= \\
\left(M_{\text {vehicle,final }} \frac{V_{\text {vehicle,final }}^{2}}{2}-M_{\text {vehicle,initial }} \frac{V_{\text {vehicle,initial }}^{2}}{2}\right)+\left(\frac{G M_{E} M_{\text {vehicle, } \text { initial }}}{r_{\text {altitude, } \text { initial }}}-\frac{G M_{E} M_{\text {vehicle,final }}}{r_{\text {altitude,final }}}\right)
\end{gathered}
$$

For early assessments of vehicle capabilities, the mechanical work and electrical work are small with respect to the propulsion work and may be ignored. Propulsion enthalpy is small, but when multiplied by the mass flow rate has a noticeable contribution to the exergy balance and should be included in the analysis. In addition, the propellant enthalpies are much larger than atmospheric enthalpies of the propellant chemical reaction products at or below 
standard atmospheric pressure and temperature such that $\mathrm{h}_{\mathrm{atm}}$ may be ignored. Similarly $\Delta \mathrm{s}$ is small for propellant chemical species with respect to atmospheric entropy of these propellants, and may be removed from the equation.

$$
\begin{aligned}
& \Delta m_{\text {prop }} \sum_{\text {stage }}\left(h_{\text {prop }}+\frac{V_{e}^{2}}{2}\right)-X_{\text {des }}=\left(M_{\text {vehicle,final }} \frac{V_{\text {vehicle,final }}^{2}}{2}-M_{\text {vehicle, initial }} \frac{V_{\text {vehicle,initial }}^{2}}{2}\right)+ \\
& \left(\frac{G M_{E} M_{\text {vehicle,initial }}}{r_{\text {altitude, initial }}}-\frac{G M_{E} M_{\text {vehicle,final }}}{r_{\text {altitude,final }}}\right) .
\end{aligned}
$$

The stages can have different propulsion types in the exergy balance relationship. The relationship supports liquid propulsion, solid propulsion, electric propulsion, nuclear propulsion, solar sails (photonic pressure), and vehicle whose boost stages are aircraft. Each stage can have a different propulsion system which is handled by the stage summation on the left hand side of the equation.

Thermodynamic exergy is a useful work relationship. It considers the useful or reversible work available to a system and thus represents the maximum useable work that the system can provide. Irreversible work is lost work and is accounted for in the $\mathrm{X}_{\mathrm{des}}$ term. Thus, exergy is always defined relative to the surrounding environment state (called the dead state). At this dead state the system can do no work. This is one of the differences with the energy balance Eq. (3) which does not consider the reference to environmental state and can thus over predict the energy available for a system. For a launch vehicle, atmospheric conditions are the dead state and this reference does change quite dramatically as the vehicle gains altitude. Thus, this changing reference state must be accounted for in launch vehicle balance equations. Because exergy balance reflects the changing dead state, the relationship allows for increased engine specific impulse $\left(\mathrm{I}_{\mathrm{sp}}\right)$ as the altitude increases and the reference atmospheric pressure approaches zero.

The exergy balance (in Eq. (6), Eq. (8), or Eq. (9)) also contains a term for the exergy destroyed, $\mathrm{X}_{\text {des. }}$ This term is related to entropy generation as $X_{\text {des }}=T_{a t m} S_{g e n}[40]$, This $\mathrm{X}_{\mathrm{des}}$ term can be expanded to include all the losses (i.e., irreversible work) in the system including vehicle drag, vehicle aero-thermal heating, trajectory errors, vehicle buffeting and vibration work, engine efficiency losses, and motor efficiency losses. The engine efficiency losses are expanded to include energy release losses $\left(\mathrm{W}_{\mathrm{ER}}\right)$, kinetic energy losses $\left(\mathrm{W}_{\mathrm{KE}}\right)$, divergence work losses $\left(\mathrm{W}_{\mathrm{div}}\right)$, and boundary layer work $\left(\mathrm{W}_{\mathrm{bl}}\right)$ as discussed in [32].

$$
\begin{aligned}
& X_{\text {des }}=W_{\text {drag }}+\left(1-\frac{T_{\text {atm }}}{T_{\text {rocket }}}\right) Q_{\text {aero }}+W_{\text {pointing }}+W_{\text {buffet }}+W_{\text {vibration }}+W_{E R}+W_{K E}+ \\
& W_{d i v}+W_{b l}+Q_{f g}
\end{aligned}
$$


Note, there is also substantial exergy lost due to staging that is not reflected in $X_{\text {des }}$ term. The kinetic and potential energy lost with lower stages as they separate is a large exergy efficiency loss to the vehicle representing work done to get the stage to altitude but not retained by the vehicle or spacecraft bus. This is accounted for in the exergy balance through the discrete change in $\mathbf{M}_{\text {vehicle }}$ at each staging event and is sometimes referred to as a gear ratio. Applying the expansion in Eq. (10) to Eq. (8) provides a complete representation of the launch vehicle.

$$
\begin{aligned}
& \left.\Delta m_{\text {prop }} \sum_{\text {stage }}\left(h_{\text {prop }}-h_{\text {atm }}\right)-T_{\text {atm }}\left(s_{\text {exh }}-s_{\text {atm }}\right)+\frac{V_{e}^{2}}{2}\right)+W_{\text {mech }}+W_{\text {elec }}-\left(W_{\text {drag }}+Q_{\text {aero }}+W_{\text {pointing }}+\right. \\
& \left.\mathrm{W}_{\text {buffet }}+\mathrm{W}_{\text {vibration }}+W_{E R}+W_{K E}+W_{\text {div }}+W_{b l}+Q_{f g}\right)=\left(M_{\text {vehicle,final }} \frac{V_{\text {vehicle,final }}^{2}}{2}-\right. \\
& M_{\text {vehicle, initial }} \frac{\left.V_{\text {vehicle, initial }}^{2}\right)}{2}+\left(\frac{G M_{E} M_{\text {vehicle, } \text { initial }}}{r_{\text {altitude, } \text { initial }}}-\frac{G M_{E} M_{\text {vehicle,final }}}{r_{\text {altitude,final }}}\right) .
\end{aligned}
$$

Thus, a single equation contains all of the key relationships for the design and operation of a launch vehicle: total performance, all the system losses, and the available work. This single relationship, then forms the integrating physics for a launch vehicle.

Note, that Eq.( 9) is a good approximation and can be used for early concept comparisons. As the design progresses, however, Eq. (11) is more appropriate to guide the design as small changes in the design will need better precision in the exergy balance. Eq. (11) also represents the rocket more completely including the hydraulic systems and electrical power systems needed for the launch vehicle or spacecraft flight.

\section{B. Exergy Efficiency}

Efficiency of a launch vehicle or spacecraft can be measured by the exergy efficiency as defined by [40]:

$$
\eta_{\text {ex }}=1-\frac{X_{\text {des }}}{X_{\text {exp }}}
$$

The $\mathrm{X}_{\text {exp }}$ term is the exergy expended by the system. For a launch vehicle or spacecraft bus this is the propulsion exergy term which is the remaining term on the left hand side of the balance equation. Thus, for a launch vehicle or spacecraft,

$$
\eta_{\text {ex }}=1-\frac{X_{\text {des }}}{X_{\text {prop }}}
$$

Thus, the efficiency of different launch vehicle configurations can be very explicitly and uniquely defined. For a launch vehicle, exergy efficiency addresses the third system property, system efficiency, posed in the paper, "How Do We Fix System Engineering?” [17] 


\section{System State Representation}

An interesting aspect of exergy is that it represents a complete set of information on the system states and properties. This section summarizes the derivation given in [41] with emphasis on system exergy. To show this, a system is defined as a multinomial distribution of $\mathrm{N}$ components with states (s) as:

$$
\mathbb{S}_{1}=N ! \prod_{i=1}^{S} \frac{q_{, i}^{n_{i}}}{n_{i} !}
$$

A launch vehicle or spacecraft has multiple subsystems, however, and so contains multiple multinomial distributions of $\mathrm{L}$ subsystems with states (s) as:

$$
\mathbb{S}=\mathbb{N} ! \prod_{N_{1}=0}^{\infty} \cdots \prod_{N_{L}=0}^{\infty} \prod_{i=1}^{s} \frac{{ }^{n_{\left\{N_{i}\right\}, i}, i}}{n_{\left\{N_{i}\right\}, i} !}
$$

For each subsystem, there are $\mathrm{N}_{\mathrm{L}}$ possible states with $\mathrm{n}_{\mathrm{i}}$ representing the number of system elements in a particular state (s) and $\mathrm{q}_{\mathrm{i}}$ is the initial distribution of the system. The system state distribution must meet a set of $\mathrm{r}$ system constraints (which also apply to Eq. (14) with the summations over $\mathrm{N}_{\mathrm{L}}$ vanishing) given by:

$$
C_{r}=\sum_{N_{1}=0}^{\infty} \cdots \sum_{N_{L}=0}^{\infty} \sum_{i=1}^{S} n_{\left\{N_{i}\right\}, i} f_{r i}, \quad \text { for } \mathrm{r}=1, \ldots, \mathrm{R}
$$

Where $\mathrm{f}_{0 \mathrm{i}}=0$ is the natural constraint. And, for the L subsystems

$$
C_{l}=\sum_{N_{1}=0}^{\infty} \cdots \sum_{N_{L}=0}^{\infty} \sum_{i=1}^{s} n_{\left\{N_{i}\right\}, i} N_{l}, \quad \text { for } \ell=1, \ldots, \mathrm{L}
$$

Eq. (14)-(17) provide a mathematically complete set of equations for a system such as a launch vehicle or spacecraft. This represents a very large set of very large matrices for a system. Making use of analytical mechanics and working mainly with Eq. (14), a set of Lagrange functions are defined for the $\ln \mathbb{S}_{1}$. This formulation is then used to show that system entropy, S, provides the "most probable distribution of the system". The term cross entropy, $\mathrm{S}_{\mathrm{x}}$, is also defined to indicate the "most probable distribution of the system" in relation to the initial conditions, $\mathrm{q}_{\mathrm{i}}$. These can be written as,

$$
\begin{gathered}
S=-C-\sum_{i=1}^{S} p_{i} \ln \left(p_{i}\right) \\
S_{x}=C+\sum_{i=1}^{S} p_{i} \ln \left(\frac{p_{i}}{q_{i}}\right)
\end{gathered}
$$

Where $\mathrm{C}$ is a constant of integration. These relationships, using the Lagrange multiplier, $\lambda \mathrm{r}$, representation from the Jayne's Relations, yield a generalized state function for the system as:

$$
\mathrm{d} \Phi_{1}=\left\{\begin{array}{l}
d S_{x}+\sum_{r=1}^{R} \lambda_{r} d Q_{r} \\
-d S+\sum_{r=1}^{R} \lambda_{r} d Q_{r}
\end{array}\right\} \leq 0
$$

Where $\mathrm{dQ}_{\mathrm{r}}=\mathrm{dU}_{\mathrm{r}}-\mathrm{dW}_{\mathrm{r}}$. 
Exergy, is defined as the difference in the systems current state and the state of the surrounding environment (i.e., the dead state). For a system defined by Eq. (15) - (17) with constraints defining the system as a control volume with heat and mass crossing the system boundaries (but no mechanical work crossing the boundaries) the state equation yields exergy as:

$$
X=\left(U-U_{a t m}\right)-T_{a t m}\left(S-s_{a t m}\right)+P_{a t m}\left(V_{\text {ol }} l_{\text {final }}-\operatorname{Vol}_{\text {initial }}\right)-\sum_{l} \mu_{l 0} m_{l}
$$

Which can be rewritten in terms of enthalpy as:

$$
X=\left(h-h_{a t m}\right)-T_{a t m}\left(S-s_{a t m}\right)-\sum_{l} \mu_{l 0} m_{l}
$$

This is the basic exergy relationship for a control volume whose boundary is at rest with respect to the external environment. Thus, the exergy relationship is derived from the complete set of system states and contains all of the information in the state function defining the system.

\section{Exergy Balance Relationships to Traditional Relationships}

Exergy balance includes both the rocket equation and the orbital energy relationship found in orbital mechanics. These relationships can be derived from the exergy balance equation. This section presents these derivations.

\section{A. Derivation of the Rocket Equation}

Exergy is not new physics for the launch vehicle but a broader and more complete relationship of the physics which define the rocket. The rocket equation is a derivative of the exergy balance equation for a launch vehicle or spacecraft bus. This derivation starts with Eq. (9), which contains many simplification of terms not explicitly addressed by the rocket equation (Eq. (1)). By differentiating Eq. (9) by the vehicle velocity the rocket equation is obtained.

The derivation makes use of the terms and limiting assumptions contained in the rocket equation:

1) The rocket equation considers only mass of the vehicle $\left(\mathrm{M}_{\mathrm{veh}}\right)$, mass of the propellant $\left(\mathrm{m}_{\text {prop }}\right)$, velocity of the vehicle $\left(\mathrm{V}_{\text {veh }}\right)$, change in the velocity of the vehicle $\left(\Delta \mathrm{V}_{\text {veh }}\right)$, and velocity of the exhaust gas $\left(\mathrm{V}_{\text {exh }}\right)$.

2) In the rocket equation derivation $V_{\text {exh }}$ is considered independent of $\Delta t$ and changes in vehicle mass (i.e. $\Delta M_{v e h}$ and $\left.\Delta \mathrm{m}_{\text {prop }}\right) . \quad V_{\text {exh }}$ is calculated as the distance from the combustion chamber to the nozzle exit over the time the exhaust gas molecules take to transit this distance. This velocity does not change over course of the trajectory flight time and therefore can be considered constant over the flight time interval. This ignores start up transients and shut 
down transients (i.e., modeled as step functions), and assumes no throttling effects on $\mathrm{V}_{\text {exh }}$ (throttling effects $\Delta \mathrm{m}_{\text {prop }}$ only).

3) Engine changes can occur with staging (i.e., different engines and different $V_{\text {exh }}$ 's can exist on different stages) which would be handled by breaking the flight trajectory into segments for each stage. $\mathrm{V}_{\text {exh }}$ can vary between segments but remains constant within the segment.

4) Note assumptions 2) and 3) make $V_{\text {exh }}$ a less reliable variable to differentiate the exergy balance equation since in some cases it would be differentiating with respect to a constant. Therefore differentiation to vehicle velocity is a better choice based on the rocket equation limiting assumptions on $\mathrm{V}_{\text {exh }}$.

5) The propellant mass is fully exhausted at the nozzle exit.

6) Losses are not considered including drag forces, aero thermal heating, gravity, etc.

Starting with Eq. (9), making use of the fact that exergy is a work relationship, and that the derivative of work yields a force relationship, differentiate with respect to the vehicle velocity, $\mathrm{V}_{\mathrm{veh}}$ :

$$
\begin{array}{r}
\frac{d}{d V_{\text {veh }}}\left[\Delta m_{\text {prop }}\left(h_{\text {prop }}+\frac{V_{\text {exh }}^{2}}{2}\right)-X_{\text {des }}\right]=\frac{d}{d V_{\text {veh }}}\left[\left(M_{\text {vehicle,final }} \frac{V_{\text {vehicle,final }}^{2}}{2}-\right.\right. \\
\left.\left.M_{\text {vehicle,initial }} \frac{V_{\text {vehicle,initial }}^{2}}{2}\right)+\left(\frac{G x M_{E} M_{\text {vehicle, initial }}}{r_{\text {altitude, initial }}}-\frac{G x M_{E} M_{\text {vehicle,final }}}{r_{\text {altitude,final }}}\right)\right]
\end{array}
$$

This yields the following:

$$
\left[\Delta m_{\text {prop }} V_{e} \frac{d V_{\text {exh }}}{d V_{\text {veh }}}-\frac{d}{d V_{\text {veh }}} X_{\text {des }}\right]=\left[\left(M_{\text {vehicle,final }} V_{\text {vehicle,final }}\right)+\left(\frac{d P E}{d V_{\text {veh }}}\right)\right]
$$

Where, the potential energy $(\mathrm{PE})$ is represented as:

$$
\mathrm{PE}=\left(\frac{G \times M_{E} M_{\text {vehicle, initial }}}{r_{\text {altitude, initial }}}-\frac{G \times M_{E} M_{\text {vehicle, final }}}{r_{\text {altitude,final }}}\right)
$$

Now, $\frac{d V_{\text {vehicle,initial }}}{d V_{\text {veh }}}=0$ since the initial velocity is a constant (fixed starting point) and with the potential energy term being represented by:

$$
\frac{d P E}{d V_{\text {veh }}}=\frac{d}{d V_{\text {veh }}}\left(\frac{G M_{E} M_{\text {vehicle, initial }}}{r_{\text {altitude,initial }}}-\frac{G M_{E} M_{\text {vehicle,final }}}{r_{\text {altitude,final }}}\right)
$$

Now, differentiate the rocket equation to find the differential relationship (constant C) for $\frac{d V_{e}}{d V_{v e h}}$. So,

$$
\frac{d V_{e}}{d V_{\text {veh }}}=C=\frac{1-\frac{M_{\text {vehicle, } \text { final }}}{M_{\text {vehicle, } \text { initial }}}}{\ln \left(\frac{M_{\text {vehicle, } \text {,initial }}}{M_{\text {vehicle, } \text { final }}}\right)}
$$

Therefore, Eq. (9) becomes, 


$$
\left[\Delta m_{\text {prop }} V_{\text {exh }} C-\frac{d}{d V_{\text {veh }}} X_{\text {des }}\right]=M_{\text {vehicle,final }} V_{\text {vehicle,final }}+\left(\frac{d P E}{d V_{\text {veh }}}\right)
$$

Now, the rocket equation does not contain loss terms (assumption 4) above) and therefore assumes that $\frac{d}{d V_{v e h}} X_{d e s}=0$ and $\frac{d P E}{d V_{v e h}}=0$.

Applying these assumptions yields,

$$
\Delta m_{\text {prop }} V_{\text {exh }} C=M_{\text {vehicle,final }} V_{\text {vehicle,final }}
$$

Now, taking the limit as $\Delta \mathrm{t}->0$ yields,

$$
d m_{\text {prop }} V_{\text {exh }}=M_{\text {vehicle,final }} d V_{\text {veh }}
$$

Where,

$$
\lim _{\Delta t \rightarrow 0} V_{\text {vehicle,final }}=d V_{\text {vehicle,final }}=d V_{\text {vehicle, } \text { initial }}+d V_{\text {veh }}=d V_{v e h}
$$

Since $d V_{\text {vehicle, initial }}=0$ as $V_{\text {vehicle,initial }}$ is a constant, then,

$$
\lim _{\Delta t \rightarrow 0} C=\lim _{\Delta t \rightarrow 0} \frac{1-\frac{M_{\text {vehicle,final }}}{M_{\text {vehicle, } \text { initial }}}}{\ln \left(\frac{M_{\text {vehicle, } \text { initial }}}{M_{\text {vehicle, } \text { final }}}\right)}=1
$$

The result of Eq. (32) is obtained by taking L'Hopitals Rule with the derivative of the top and bottom with respect to time (t). Now, using the mass balance written as,

$$
M_{\text {vehicle,final }}=M_{\text {vehicle, } \text {,initial }}-\Delta m_{\text {propellant }}
$$

Then,

$$
d M_{\text {veh }}=d M_{\text {vehicle, } \text { iniital }}-d m_{\text {prop }}=-d m_{\text {prop }}
$$

Since, $d M_{\text {vehicle, } \text {,inital }}=0$ as $M_{\text {vehicle, } \text {,iniital }}$ is constant. Therefore,

$$
-d M_{v e h} V_{\text {exh }}=M_{\text {vehicle,final }} d V_{\text {veh }}
$$

Grouping terms and integrating,

$$
-V_{\text {exh }} \int \frac{1}{M_{\text {vehicle }}} d M_{\text {veh }}=\int d V_{\text {veh }}
$$

Which results in the rocket equation, Eq. (1)

$$
V_{\text {exh }} \ln \left(\frac{M_{\text {vehicle, } \text { initial }}}{M_{\text {vehicle, } \text { final }}}\right)=\Delta V_{\text {vehicle }} .
$$

Note, that this derivation involves the differentiation of the exergy balance equation to obtain the rocket equation. Essentially, the exergy balance is the integration of the rocket equation over the vehicle velocity during flight with the integration constants defined as the exergy destruction term, Xdes, and the potential energy term. 
The final integration in Eq. (36) is removing the differential changes in vehicle mass and velocity from the derivation and is also used when deriving the rocket equation from the momentum relationships.

\section{B. Derivation of the Orbital Energy Relationship}

The energy balance relationships for a spacecraft in orbit are also contained in the exergy balance relationship. For a spacecraft bus that is thrusting, the exergy balance equation directly contains the relationship between spacecraft energy and thrust. This is seen directly in Eq. (9) above.

Now, for a vehicle coasting in orbit around a body (i.e. planet, moon or sun) then the propulsion components are zero and Eq. (9) reduces to:

$$
0-X_{\text {des }}=\left(M_{\text {vehicle,final }} \frac{V_{\text {vehicle,final }}^{2}}{2}-M_{\text {vehicle, initial }} \frac{V_{\text {vehicle, }, \text { initial }}^{2}}{2}\right)+\left(\frac{G x M_{B} M_{\text {vehicle, } \text { initial }}}{r_{\text {altitude, } \text { initial }}}-\right.
$$

$\left.\frac{G x M_{B} M_{\text {vehicle,final }}}{r_{\text {altitude,final }}}\right)$.

Combining terms on the right hand side of Eq. (37) yields:

$$
\begin{aligned}
& X_{\text {des }}=\left(M_{\text {vehicle, final }} \frac{V_{\text {vehicle,final }}^{2}}{2}-\frac{G x M_{B} M_{\text {vehicle,final }}}{r_{\text {altitude,final }}}\right)-\left(-\frac{G \times M_{B} M_{\text {vehicle,initial }}}{r_{\text {altitude, } \text { initial }}}+\right. \\
& \left.M_{\text {vehicle, } \text { initial }} \frac{V_{\text {vehicle, } \text {,initial }}^{2}}{2}\right) .
\end{aligned}
$$

Now, the orbital energy for a spacecraft is:

$$
E_{\text {vehicle }}=\left(M_{\text {vehicle }} \frac{V_{\text {vehicle }}^{2}}{2}-\frac{G x M_{B} M_{\text {vehicle }}}{r_{\text {altitude }}}\right) .
$$

Using this relationship to simplify Eq. (38) yields,

$$
X_{\text {des }}=\left(E_{\text {vehicle,final }}\right)-\left(E_{\text {vehicle, initial }}\right)=\Delta E_{\text {vehicle }} .
$$

Now, Xdes is zero for a vehicle that is not thrusting and expends no other stabilization energy (e.g., control moment gyroscopes). So, treating the spacecraft as a static mass,

$$
\Delta E_{\text {vehicle }}=\left(E_{\text {vehicle,final }}\right)-\left(E_{\text {vehicle, } \text { initial }}\right)=0 .
$$

Thus there is no change in the spacecraft energy which is as expected for a spacecraft in orbit around a body where kinetic and potential energy changes are balanced. Note that for a vehicle with an active system for stabilization or station keeping (e.g., control moment gyroscope, thrusters, spin stabilization), these systems would be added to the left-hand side of Eq. (37) and Eq. (11) and the vehicle orbital energy change would be related to the work done by the stabilization or station keeping system and the associated losses. 


\section{Systems Engineering Application of Exergy}

As the integrating physics relationship for launch vehicles and spacecraft, exergy provides a fundamental system property. This property provides systems engineers with the ability to design, model, and analyze the system at the system level. A specific example of the application of system exergy to a launch vehicle is to illustrate the analysis and integration capabilities provided by this approach. The application to spacecraft is also shown, setting the foundation for further work. Finally, a discussion of the application of system exergy is provided across the system engineering lifecycle.

\section{A. Apollo 17 Exergy Efficiency}

To illustrate the application of exergy to a launch vehicle, the Saturn V Apollo 17 mission was analyzed. The Saturn V vehicle (AS-512) consisted of 3 stages with a payload consisting of a Command Module (CM), Service Module (SM), and Lunar Excursion Module (LEM). The first stage (S-1C) consists of the propellant (liquid oxygen $\left(\mathrm{LO}_{2}\right)$ and Refined Petroleum (RP)) feeding $5 \mathrm{~F}-1$ engines. The second stage (S-II) consists of the propellant $\left(\mathrm{LO}_{2}\right.$ and liquid hydrogen $\left(\mathrm{LH}_{2}\right)$ ) feeding $5 \mathrm{~J}-2$ engines. The third stage (S-IVB) consists of the propellant $\left(\mathrm{LO}_{2}\right.$ and $\left.\mathrm{LH}_{2}\right)$ feeding a single $\mathrm{J}-2$ engine, the instrument unit, and the payload modules.

The data for the analysis is taken from the Apollo 17 Flight Evaluation Report. The report has several good figures and plots of the flight data which were translated at discrete points into a spreadsheet to calculate the exergy balance equation. For Saturn V missions, a system assessment would require evaluation of over 20 figures and data tables contained in the flight evaluation report. These figures and tables included information on trajectory paths; engine start up, main stage, and shutdown (for all 11 engines contained by the vehicle); vehicle and propellant masses; propulsive venting, mission event times, electrical power, etc. At the time of the Apollo Program, this data was reviewed and a subjective assessment of the system performance could then be stated. Exergy efficiency provides a single integrated assessment of these multiple data forms to provide an objective assessment of vehicle performance. Key parameters and units used in the exergy analysis are given in Table 1. Note that English units were used in the analysis. Not all of the information needed for Eq. (11) is contained in the Flight Evaluation Report (e.g., specific engine efficiency losses, hydraulic system work) so Eq. (9) is used for this analysis.

Now referring to Table 1 and Eq. (9), $\Delta \mathrm{m}_{\text {prop }}$ for each stage can be calculated by the difference in each stages remaining propellant along the Vehicle Flight Time. Similarly, the change in $\mathbf{M}_{\mathrm{veh}}$ as part of the vehicle's change in kinetic energy is the change in the Vehicle Mass. The change in vehicle mass accounts for the change in stage 
propellant mass, including the 2 Auxiliary Propulsion Systems (APS), and staging events. $\mathrm{V}_{\text {veh }}$ is the inertial velocity and $r_{\text {altitude }}$ is the altitude above the surface of the earth. The enthalpy of the propellant, $h_{\text {prop }}$, is calculated using a power balance program based on data from the engines.

Table 1 AS-512 Data Parameter Types

\begin{tabular}{|l|l|}
\hline Vehicle Flight Time (sec) & Altitude (ft) \\
\hline Inertial Velocity (ft/sec) & Vehicle Mass (Ibm) \\
\hline S-1C Propellant Remaining (Ibm) & S-II Propellant Remaining (Ibm) \\
\hline S-IVB Propellant Remaining (Ibm) & $\begin{array}{l}\text { Auxiliary Propulsion System (1 and 2) Mass } \\
\text { Remaining (lbm) }\end{array}$ \\
\hline S-IC Isp $(\mathrm{sec})$ & S-II I sp $_{\text {(sec) }}$ \\
\hline S-IVB Isp $(\mathrm{sec})$ & \\
\hline
\end{tabular}

Using the AS-512 fight data the exergy efficiency for the mission is calculated using Eq. (9) across the Vehicle Flight Time in Matlab. Fig. 1 shows the plot against vehicle velocity of the efficiency through separation of the payload modules from the S-IVB.

The integrated nature of the exergy balance equation and exergy efficiency can be seen in Fig. 1. The key aspects of the flight performance are evident in the exergy efficiency plot. Maximum aerodynamic pressure (Max Q) is seen early in the flight. The stage separation events are clearly seen in the efficiency drops. This is the result of the energy put into the mass of the stage and then jettisoned at separation. This loss of vehicle energy in the expended stage is a loss in exergy of the system. Also seen in the plot are the major engine events including engine cut offs and mixture ratio shifts. On the first and second stage of the Saturn V, the center engine is cut off before the outer engines. This is seen as a slope change in the efficiency plot indicating a less efficient operation of the system after the center engine cut off. The engine mixture ratio shift also creates a slope change and is a more efficient operation after the shift. The degradation of efficiency and the decrease in vehicle velocity late in flight reflects the potential energy drag on the vehicle as it moves away from the earth and slows once the S-IVB engine is cut off.

Finally, the separation of the Command/Service Module (CSM) and the LEM occur as separate events during the coast phase (constant velocity over the time period of these operations). Thus these events all occur on a vertical line when plotting against vehicle velocity. The bottom point is the initial separation of the CSM. The upper end of the line is the docking maneuver to capture the LEM where the stage and CSM are recombined as a higher mass system. Since potential energy is increasing with the large change in distance from Earth over the maneuver time frame, a large efficiency increase is seen. The star $(*)$ on the vertical line at $25,343 \mathrm{ft} / \mathrm{sec}$ indicates the exergy efficiency of the 
CSM/LEM after final S-IVB separation at $12.86 \%$. Note this efficiency gives a gear ratio of the Saturn system as 7.8 accounting for both the energy expended and mass changes in the system.

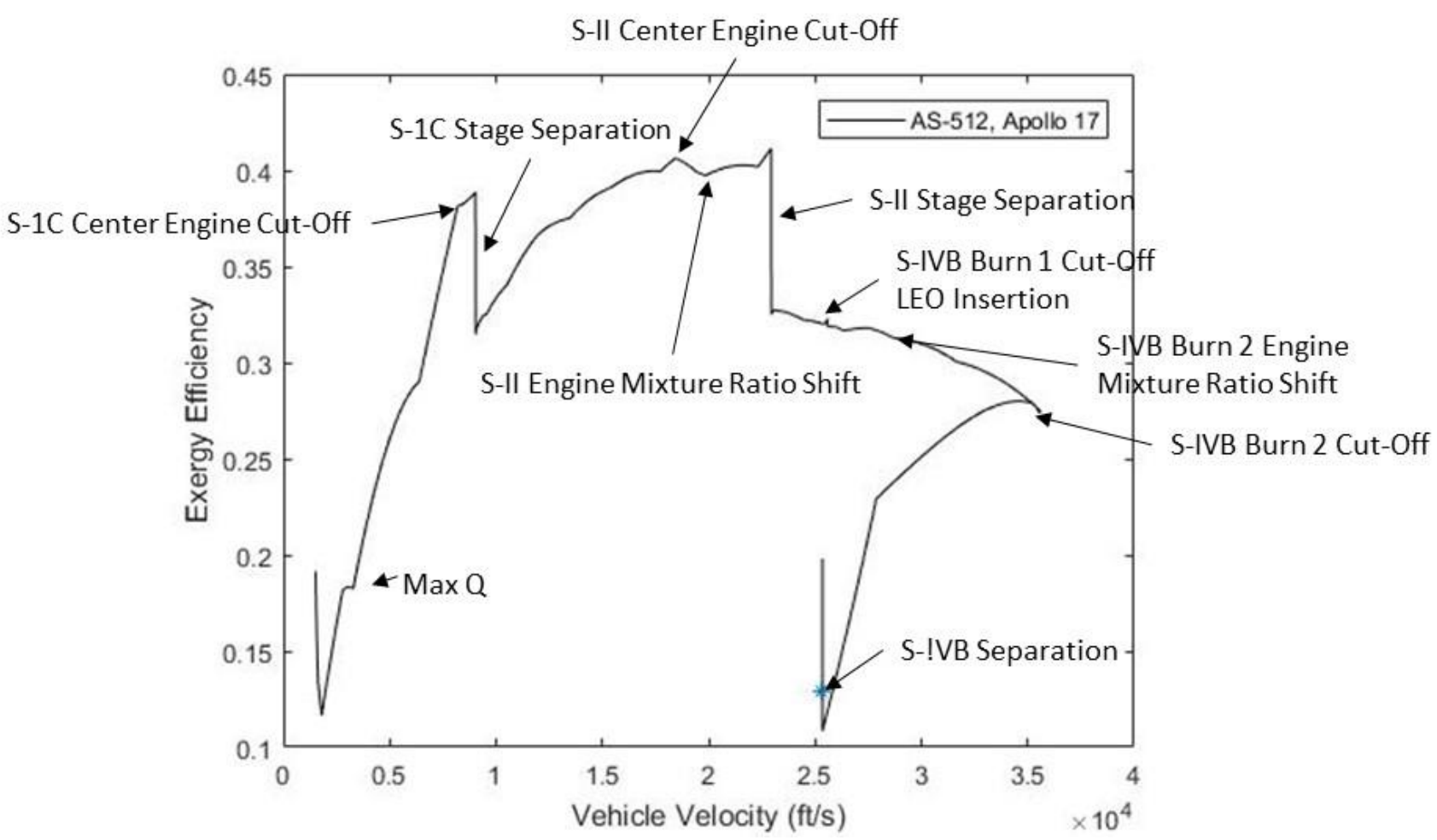

Fig. 1 AS-512 Apollo 17 Exergy Efficiency Plot

\section{B. Spacecraft Exergy Efficiency}

Spacecraft have multiple parts and fly in a variety of trajectory reference frames. This section will look at the application of exergy in the integration of the parts of the spacecraft. Then, the different trajectory reference frames will be considered and their effect on the exergy balance.

\section{Spacecraft Exergy Integration}

Spacecraft have multiple parts that can have different integrating physics relationships. Some of the considerations for understanding this include: crewed vs un-crewed; instrument types; ascent vs descent. The spacecraft bus is a thermodynamic system and system exergy represents the integrating physics for the bus. The various instruments attached to the bus are integrated more by their sensitivity to the specific phenomena that they are measuring or monitoring. For example, optical systems are integrated through their imaging or non-imaging (i.e., light gathering) performance. For these optical systems, the optical transfer function provides the integrating physics relationships 
incorporating the spacecraft bus exergy showing how the various aspects of the system effect the optical imaging or non-imaging performance [42]. For these instruments, the spacecraft bus becomes an important input to their system performance.

For crewed spacecraft, the propulsion system module (e.g., service module in Apollo) is a thermodynamic system and system exergy represents the integrating physics for the SM as defined by Eq. (11). The crew module (or command module on Apollo), however, is not a propulsive system. Its main physics are driven by the maintenance of a habitable crew environment within the crew compartment(s). The environmental control and life support system (ECLSS) manages this environment. The crew environment is the reference state for the ECLSS with its functions measured against maintaining this environment. Exergy incorporates the electrical, thermal, chemical, and biological balance through an integrated relationship in the exergy balance equation. Eq. (42) shows the basic exergy balance for an ECLSS system.

$$
\begin{aligned}
& \Delta \boldsymbol{X}_{\text {ECLSS }}=\sum_{\text {process }} \boldsymbol{m}_{\text {fluid }}\left(\left(\boldsymbol{h}_{\text {final }}-\boldsymbol{h}_{\text {cabin }}\right)-T_{\text {cabin }}\left(\boldsymbol{s}_{\text {final }}-\boldsymbol{s}_{\text {cabin }}\right)+\left(\frac{\boldsymbol{V}_{\text {final }}^{2}}{2}\right)\right)- \\
& \sum_{\text {process }} \boldsymbol{m}_{\text {fluid }}\left(\left(\boldsymbol{h}_{\text {initial }}-\boldsymbol{h}_{\text {cabin }}\right)-T_{\text {cabin }}\left(\boldsymbol{s}_{\text {initial }}-\boldsymbol{s}_{\text {cabin }}\right)+\left(\frac{\boldsymbol{v}_{\text {initial }}^{2}}{2}\right)\right)+\sum\left(1-\frac{T_{\text {cabin }}}{T_{\text {crew }}}\right) Q_{\text {crew }}- \\
& \sum\left(\frac{T_{\text {cabin }}-T_{\text {coolant }}}{T_{\text {coolant }}}\right) Q_{T M S}+\sum \boldsymbol{W}_{\boldsymbol{E P S}}-\boldsymbol{P}_{\text {cabin }}\left(\boldsymbol{V}_{\text {ol }}\right. \text { final } \\
& \left.-\boldsymbol{V o l}_{\text {initial }}\right)-\boldsymbol{X}_{\text {des }}
\end{aligned}
$$

Eq. (42) shows that the cabin thermal conditions, chemical reactions (through the enthalpy and entropy terms), equipment electrical power, cabin volume, mechanical work, and crew biological and thermal contributions are all balanced in the exergy relationship. Thus, system exergy provides the integrating physics for the spacecraft crew compartments. An analysis of the International Space Station ECLSS system exergy is provided in [28].

Finally, spacecraft can be differentiated by ascent and descent capabilities. The ascent stage or stages are essentially a launch vehicle and have the same basic exergy balance. Thus, ascent stage exergy balance is defined by Eq. (11) (or Eq. (9)).

Planetary atmospheric entry is a thermodynamic process and is also integrated by system exergy. In this case the velocity of the spacecraft is toward the planet during re-entry as opposed to away from the planet for a launch vehicle or ascent stage. The exergy balance in this case is given by:

$$
\boldsymbol{X}_{\text {des }}=\left(-M_{\text {vehicle,final }} \frac{V_{\text {vehicle, } \text { final }}^{2}}{2}+M_{\text {vehicle, } \text { initial }} \frac{V_{\text {vehicle, } \text {,initial }}^{2}}{2}\right)-\left(\frac{G M_{E} M_{\text {vehicle, } \text { initial }}}{r_{\text {altitude, initial }}}-\right.
$$

$\left.\frac{G M_{E} M_{\text {vehicle, final }}}{r_{\text {altitude,final }}}\right)$. 
The $\mathrm{X}_{\mathrm{des}}$ term on the left hand side is dominated by the aero-thermal heating and drag losses during re-entry. Since $\mathrm{X}_{\text {des }}$ is the only term remaining on the left hand side, the negative sign has been moved to the right hand side which reflects the loss of spacecraft kinetic energy and potential energy with respect to the planet during re-entry.

Looking at these various applications of system exergy to spacecraft, it is seen that system exergy provides the integrating physics for the spacecraft bus, crew modules, and re-entry. The system exergy of the spacecraft bus is also the integrating input to the integrating physics of the instrument modules aboard the spacecraft. Thus, system exergy is the key integrating relationship in spacecraft design.

\section{Spacecraft Reference Frames}

The results of the derivation in Eq. (37)-(41) are general for a two body system. When applying exergy balance to a specific system, the body reference frame is important. Interplanetary travel involves the use of a heliocentric orbit with $\mathrm{M}_{\mathrm{E}}$ in Eq. (9) or (11) being replaced with $\mathrm{M}_{\mathrm{S}}$ (the mass of the sun). This is a very large value and the application of exergy requires employing the planetary motions as boundary conditions for the planetary transfer. The spacecraft essentially has the starting velocity and distance to the sun ( $\mathrm{r}_{\text {altitude }}$ in Eq. (9), (11) and Eq. (39)) that the departure planet has and must achieve the final velocity and solar distance that the arrival planet has. The velocity and distances may also be adjusted based on the actual planetary orbit the spacecraft has relative to the body at departure or insertion orbit at arrival. These velocity and distance values set the kinetic and potential energy of the spacecraft before the departure burn and after the insertion burn.

When operating within a planetary body's sphere of influence (SOI), the sphere in which the planetary gravitational influence is greater than the sun's influence, then the solar influence can usually be ignored. In this case a planetary centric (geocentric reference system for the Earth) can be used. Eq. (44), gives the general relationship for the planetary SOI [43].

$$
r_{\text {SOI }}=R_{\text {sun }, \text { planet }}\left(\frac{M_{B}}{M_{S}}\right)^{2 / 5}
$$

Thus, the exergy balance for a spacecraft in a geocentric orbit, can be initially calculated using the Earth reference frame. More detailed effects on the spacecraft orbit can be brought into (11) by adding the terms for the solar potential energy and the moon potential energy as shown in Eq. (45). In these cases, the distance of the spacecraft to the sun or to the moon must account for all of the body motions (i.e., earth around the sun, moon around the earth, spacecraft around the earth) in order to properly calculate the distance to each body as the spacecraft orbits the planet. Thus, exergy does account for all the effects on the spacecraft orbital trajectory as found in orbital mechanics. 


$$
\begin{aligned}
& \left.\Delta m_{\text {prop }} \sum_{\text {stage }}\left(h_{\text {prop }}-h_{\text {atm }}\right)-T_{\text {atm }}\left(s_{\text {exh }}-s_{\text {atm }}\right)+\frac{V_{e}^{2}}{2}\right)+W_{\text {mech }}+W_{\text {elec }}-\left(W_{\text {drag }}+Q_{\text {aero }}+W_{\text {pointing }}+\right. \\
& \left.\mathrm{W}_{\text {buffet }}+\mathrm{W}_{\text {vibration }}+W_{E R}+W_{K E}+W_{\text {div }}+W_{b l}+Q_{f g}\right)=\left(M_{\text {vehicle,final }} \frac{V_{\text {vehicle,final }}^{2}}{2}-\right. \\
& \left.M_{\text {vehicle,initial }} \frac{V_{\text {vehicle,initial }}^{2}}{2}\right)+\left(\frac{G M_{E} M_{\text {vehicle, initial }}}{r_{\text {altitude,initial }}}-\frac{G M_{E} M_{\text {vehicle,final }}}{r_{\text {altitude,final }}}\right)+\left(\frac{G M_{S} M_{\text {vehicle, initial }}}{d_{\text {solar,initial }}}-\frac{G M_{S} M_{\text {vehicle,final }}}{d_{\text {solar,final }}}\right)+ \\
& \left(\frac{G M_{m} M_{\text {vehicle,initial }}}{d_{\text {moon,initial }}}-\frac{G M_{m} M_{\text {vehicle,final }}}{d_{\text {moon,final }}}\right) .
\end{aligned}
$$

\section{Systems Engineering Benefits}

Systems exergy enables a significant systems engineering advance over traditional methods in the design, analysis, and integration of systems. These advances can be seen across the system lifecycle phases from system concept selection through system operations.

\section{Traditional Launch Vehicle and Spacecraft Systems Engineering Approach}

Systems engineering brings a focus on processes to guide a system development activity. While these processes are necessary, they mainly focus on organization and information flow though the various disciplines needed to develop the system by the organization. This does not necessarily maintain a focus on the system, but rather on the way the system is developed. A more system focused approach is needed in order to effectively and efficiently design a system. [17]

Traditional methods of system analysis evaluation involve a set of plots and tables to view the integrated performance of the system. These include trajectory vs. time, trajectory vs. velocity, engine thrust, engine Isp, engine mixture ratio, and propellant mass flow rate as shown in Table 2. These have evolved over the history of spaceflight as the key system performance parameters and provide a segmented system understanding based on various engineering discipline measures. Use of these parameters for concept selection is difficult, requiring a level of preliminary design to be accomplished in order to establish some stability and certainty in the parameter values. Even if this depth of understanding is achieved, the comparison of configuration options is still difficult to discern leading to subjective results.

In addition, system integration of these different performance parameters has been difficult and the subtleties of their interactions are not always easily discerned. This leads to a bottoms up approach to system design where key parameters are developed, sometimes independently, and then compiled into a set to see if they provide sufficient 
system performance. This can be awkward in integration, difficult to comprehend, and difficult to control as the system design progresses.

\section{Systems Exergy in Concept Selection}

Systems exergy provides an ability to objectively compare different configurations, even different configuration types of launch vehicles and spacecraft during concept selection. A detailed comparison of various launch vehicle types including both liquid and solid rocket motor configurations is provided in [23] and [24]. Exergy efficiency provides the objective measure to determine the most efficient configuration. This includes not only the balance of propulsion provided energy with the vehicle kinetic energy and potential energy but also the vehicle losses. The launch vehicle losses included in the exergy balance equation include: staging losses, propulsion efficiency, aerodynamic drag, aero-thermal heating, aerodynamic buffeting, and vibration. Except for the staging losses, these

loss components are included as part of the $\mathrm{X}_{\text {des }}$ term. As seen in Fig. 1, the staging losses represent a large drop in system efficiency as the dry mass of the stage or booster contains a large portion of the system exergy in the form of kinetic and potential energy that is lost to the payload upon separation. Aerodynamic drag and aero-thermal losses are a very small portion of the total system losses as discussed in [26]. Thus, exergy efficiency provides a single measure representing the total system performance across the trajectory path. This provides a critical parameter for use in system concept selection.

\section{Systems Exergy in System Design}

As the system development progresses into system design, system exergy provides the key tool to integrate and guide the various discipline engineering design efforts from a system perspective. As shown in Table 2, exergy balance incorporates several key parameters from the different launch vehicle engineering disciplines. Exergy balance therefore, is the systems engineering tool to establish a set of design parameters to guide the various discipline design efforts such that the initial design analysis cycle guidelines represent a physically realizable balance. As the design progresses, the exergy balance model provides the integration tool to incorporate the discipline design parameters and confirm that the resulting designs balance (or "close").

The systems exergy balance equation provides the key system integration model representation. A systems model should model the system with contributions from each of the engineering design disciplines. Systems exergy provides the medium to construct this model, with input from each of the engineering disciplines of key system performance parameters. This provides an important system modeling basis for systems engineering. 
This application answers a second property of system engineering posed in [17], which asks if the system implementation is effective in achieving its intended results. Exergy provides a mechanism to maintain an effective design at the system level, providing a measure of system effectiveness as well as system efficiency (mentioned earlier).

\section{Systems Exergy in Operations}

The systems exergy balance equation provides important information to the development of system operations.

The system exergy balance can be evaluated across the possible system variations to determine the nominal system operating boundaries. This provides guidance to the development of operational procedures for the vehicle and responses to vehicle constraint violations. The balance equation is also the starting point for any block upgrades, maintenance repair actions, or obsolescence management changes. The solutions to these changes can be assessed looking at the change in the system exergy balance, providing guidance or the positive or negative improvement to the system as options are considered and developed.

\section{Conclusion}

Traditional launch vehicle design and analysis has focused on system mass and mass margins. The system mass is a critical property of the system but not the integrating property of the system. The orbit to be achieved is an energy relationship, yet this relationship is limited and must account for the limitations imposed by the second law of thermodynamics. The ideal rocket equation is a relationship which the launch vehicle design must meet but by itself does not provide an integrated system equation. With the pad velocity and orbital insertion velocity set, only system mass is left as a variable which is not an integrating system relationship. Key parameters such as gravity, aerodynamic drag, or propulsion efficiencies are not explicitly or directly represented by the rocket equation. System exergy provides a relationship which incorporates all of these into a single system to provide an integrated system design and analysis relationship.

System exergy has been shown to contain all of the thermodynamic information about the system. This was further demonstrated by differentiating the exergy balance equation to arrive at the rocket equation showing the exergy balance is the result of integrating the rocket equation over vehicle velocity. The spacecraft orbital energy was also shown to be contained in the exergy balance relationship.

Systems exergy provides the key integrating relationship for spacecraft, crewed and uncrewed in the various planetary transfer reference frames. Spacecraft busses, crew cabins, and re-entry systems are all integrated by systems 
exergy. Spacecraft instruments may have different integrating physics relationships, yet systems exergy is the integrating input between the spacecraft bus in the instrument package.

System analysis and design of launch vehicles has also involved the cognitive integration of a variety of vehicle performance parameters. Each parameter indicating a particular aspect of the system. These parameters are tightly coupled to each but reviewing these independently does not yield the system interactions or a total evaluation of the system performance. System exergy provides an integrated thermodynamic approach to assess the launch vehicle and spacecraft as a fully integrated system, integrating the various performance parameters in a single relationship. This allows the specific efficiency of a system to be calculated. With calculated efficiency accounting for all system factors, different launch vehicles can now be compared with an objective assessment of their performance.

Systems exergy is a key systems engineering relationship enabling the efficiency and effectiveness of the system design to be measured. Since system exergy contains all of the thermodynamic information about the system, it provides the basis for system integration as it brings all of the system thermodynamic properties into a single integrated relationship. By establishing the integrating physics relationship for launch vehicle and spacecraft, system exergy opens the door to clear evaluations of launch vehicle and spacecraft options and provides a much more concise guidance of their design and analysis.

\section{Acknowledgments}

This work began as a series of lunch discussions with former NASA Administrator, Michael Griffin. Mike and I discussed the various aspects of launch vehicle design and what the integrating physics actually are. After discussing mass relationships, my initial suggestion was the energy relationship. Mike suggested that we would also need to consider entropy in this context. In researching the entropy relationships I discovered the work by the Air Force Research Laboratory (AFRL)-Wright-Patterson. AFRL-WP/Jose Camberos, University of Dayton/John Doty, and Missouri University of Science and Technology/David Riggins had contributed to a book on thermodynamic exergy looking at aircraft, including hypersonics [1]. This work provided an excellent understanding for the derivation of the launch vehicle relationships contained in this paper. A great deal of credit goes to Mike in helping inspire and focus this effort and to Jose, John, and Dave for their advice in understanding and applying exergy analysis properly. 


\section{References}

[1] Camberos, J., Moorhouse, D. J., "Exergy Analysis and Design Optimization for Aerospace Vehicles and Systems", AIAA, Va., 2011.

[2] Gilbert, A., Mesmer, B., Watson, M. D., "Uses of Exergy in Systems Engineering", Conference on Systems Engineering Research, Huntsville, Alabama, 2016.

[3] Luther, M. B., Hall, T. W., “Exergy Applied to Lunar Base Design”, 40th AIAA International Conference on Environmental Systems, Barcelona, Spain, July 2010.

[4] Berg, F. T. N., Balchin, M. J., Keogh, P. S., "New Principles for Dynamic Aircraft Exergy Mapping", AlAA Journal of Aircraft, Vol. 50, No. 4, July-August 2013, pp. 1088-1098.

[5] Arntz, A., Hue, D., "Exergy-Based Performance Assessment of the NASA Common Research Model", AIAA Journal, Vol. 54, No. 1, January 2016, pp. 88-100.

[6] Pellegrini, L. F., Gandolfi, R., Silva, G. A. L., Oliveira, S., "Exergy Analysis as a Tool for Decision Making in Aircraft Systems Design, 45th AIAA Aerospace Sciences Meeting, Reno, Nevada, January 2007.

[7] Alabi, K., Ladeinde, F., "Utilizing CFD-Based Exergy Calculations in the Design/Optimization of a Complete Aircraft System", 45th AIAA Aerospace Sciences Meeting, Reno Nevada, January 2007.

[8] Abbas, M., Riggins, D. W., "Exergy-Based Performance Analysis of a Turbojet Engine", 52nd AIAA Joint Propulsion Conference, Salt Lake City, Utah, July 2016.

[9] Bracey, M., Nuzum, S., Roberts, R. A., Wolff, M., Zumberge, J., “Air Cycle Machine Transient Modeling with Exergy Analysis", 14th AIAA International Energy Conservation Engineering Conference, Salt Lake City, Utah, July 2016.

[10] Moorhouse, D. J., "Proposed System-Level Multidisciplinary Analysis Technique Based on Exergy Methods", AIAA Journal of Aircraft, Vol. 40, No. 1, January-February 2003, pp. 11-15.

[11] Etele, J., Rosen, M. A., “Exergy Losses for Aerospace Engines: Effect of Reference-Environments on Assessment Accuracy", 38th AIAA Aerospace Sciences Meeting, Reno, Nevada, January 2010.

[12] Sohret, Y., Ekici, S., Altuntas, O., Hepbasli, A., Karakoc, T. H., "Exergy as a Useful Tool for the Performance Assessment of Aircraft Gas Turbine Engines: A Key Review", Progress in Aerospace Sciences 83, 2016, pp. 57-69.

[13] Jiang, H., Dong, S., Zhang, H., "Energy Efficiency Analysis of Electric and Conventional Environmental Control System on Commercial Aircraft", IEEE International Conference eon Aircraft Utility Systems, Beijing, China, October 2016.

[14] Bellini, R., Lu, F. K., "Exergy Analysis of a Pulse Detonation Power Device", AIAA Journal of Propulsion and Power, Vol. 26, No. 4, July-August 2010, pp. 875-877.

[15] Brilliant, H. M., "Analysis of Scramjet Engines Using Exergy Methods", 31st AIAA Jet Propulsion Conference, San Diego, CA, July 1995.

[16] Hayes, D., Lone, M., Whidborne, J. F., Coetzee, E., "Evaluating the Rationale for Folding Wing Tips Comparing The Exergy and Breguet Approaches", 55th AIAA Aerospace Sciences Meeting, Grapevine, Texas, January 2017.

[17] Griffin, M. D., "How Do We Fix System Engineering?", 61st International Astronautical Congress, Prague, Czech Republic, 27 September - 1 October 2010, pp. 1-9.

[18] Moorhouse, D. J., Camberos, J. A., "Systems Engineering in Terms of Exergy", AlAA 39th Thermophyics Conference, Miami, FL, June 2007.

[19] Doty, J. H., Camberos, J. A., "Statistical, Modular Systems Integration Using Combined Energy and Exergy Concepts", 48th AIAA Aerospace Sciences Meeting, Orlando, Florida, January 2010.

[20] Camberos, J. A., "On the Construction of Exergy Balance Equations for Availability Analyses", 8th AIAA/ASME Joint Thermophysics and Heat Transfer Conference, St. Louis, Missouri, June 2002.

[21] Doty, J. H., Camberos, J. A., Moorhouse, D. J., "Benefits of Exergy-Based Analysis for Aerospace Engineering Applications: Part 1", 40th AIAA Thermophysics Conference, Seattle, Washington, June 2008.

[22] Doty, J. H., Camberos, J. A., Moorhouse, D. J., "Benefits of Exergy-Based Analysis for Aerospace Engineering Applications: Part 2", 47th AIAA Aerospace Sciences Meeting, Orlando, Florida, January 2009.

[23] Gilbert, A., Mesmer, B., Watson, M. "Exergy Analysis of Rocket Systems", 9th Annual IEEE International Systems Conference, Vancouver, BC, April, 2015 
[24] Watson, M. D., Gilbert, A., Mesmer, B., "Launch Vehicle Exergy Efficiency Analysis", JANNAF 43 ${ }^{\text {rd }}$ SMBS/39 ${ }^{\text {th }}$ PEDCS $/ 30^{\text {th }}$ RNTS $/ 28^{\text {th }}$ SEPS Joint Subcommittee Meeting, Salt Lake City, Utah, December 2015.

[25] Gilbert, A., Mesmer, B., Watson, M.D., "Exergy Based Optimization of Rocket System Staging Times,” IEEE International Systems Conference, Orlando, Florida, April 18-21 2016.

[26] Watson, M.D., Gilbert, A., Mesmer, B., "Assessment of Exergy Destruction in Space Launch Vehicles", Proceedings of the11th Modeling and Simulation, JANNAF, Phoenix, Arizona, December, 2016.

[27] Watson, M. and Farrington P., "NASA systems engineering research consortium: Defining the path to elegance in systems, Proceedings of the 2016 Conference on Systems Engineering Research, Huntsville, AL, Mar 22-Mar

24, 2016.

[28] Clem, A. K., Nelson, G. J., Mesmer, B., Watson, M. D., Perry, J. L., "Exergy Based Analysis for the Environmental Control and Life Support Systems of the International Space Station", Proceedings of the AIAA Space Conference, September 2016.

[29] Serway, R. A., Physics for Scientist and Engineers, Saunders Publising, 1982, pp. 181.

[30] Serway, R. A., Physics for Scientist and Engineers, Saunders Publising, 1982, pp. 286.

[31] Kibbey, T. P., Rho-Isp Revisited and Basic Stage Mass Estimating for Launch Vehicle Conceptual Sizing Studies, AIAA, 2015.

[32] Sack, W., Kishimoto, K., Ogawara, A., Yoshikawa, K., Atsumi, M., "The MB-60 Cryogenic Upper Stage Engine - A World Class Propulsion System", AIAA, 2009.

[33] Cengel, Y. A., Boles, M. A., Thermodynamics An Engineering Approach, $7^{\text {th }}$ Edition, McGraw Hill Publishing, NY, 2011, pp 12-15.

[34] Cengel, Y. A., Boles, M. A., Thermodynamics An Engineering Approach, $7^{\text {th }}$ Edition, McGraw Hill Publishing, NY, 2011, pg. 425.

[35] Borgnake, Sonntag, "Fundamentals of Thermodynamics", Chapter 8: Exergy, John Wiley and Sons, NY, 2013, pp. 362-402.

[36] Moran, M. J., Shapiro, H. N., Boettner, D. D., Bailey, M. B., "Fundamentals of Engineering Thermodynamics”, Chapter 7: Exergy Analysis, John Wiley and Sons, NY, 2014, pp. 369-436.

[37] Klein, S., Nellis, G., "Thermodynamics”, Chapter 7: Exergy, Cambridge University Press, NY, 2012, pp. 350-384

[38] Kroos, K. A., Potter, M. C., "Fundamentals of Thermodynamics", Section 6.6: Exergy (Availability) and irreversibitliy, Cengage Learning, NY, 2015, pp. 230-236.

[39] Dincer, I., Rosen, Marc A., "EXERGY”, Elsevier, NY, 2007.

[40] Cengel, Y. A., Boles, M. A., Thermodynamics an Engineering Approach, $7^{\text {th }}$ Edition, McGraw Hill Publishing, NY, 2011, pg. 444.

[41] Niven, R. K., from: arXiv:cond-mat/0512017, 2007, pp. 26-27.

[42] Watson, M. D. and Pryor, J. E., "Systems Engineering of Photonic Systems for Space Applications", in Nanophotonics and Microphotonics for Space Environments VIII, SPIE, 2014.

[43] Curtis, Howard, D., “Orbital Mechanics for Engineering Students”, $3^{\text {rd }}$ ed., Elsevier, Boston, 2014, pp. 413-416. 